\title{
A LINGUAGEM ENTRE DOIS MUNDOS NA OBRA $O$ LUGAR, DE ANNIE ERNAUX
}

\section{VIEIRA, Vanessa Ferreira ${ }^{1}$}

RESUMO: Este artigo reflete as questões sociais apontadas na obra $O$ lugar, da escritora francesa Annie Ernaux, tendo como foco o afastamento entre a autora-narradora e seu pai, personagem principal. A análise levará em consideração a expressão "trânsfuga de classe", cunhada por Pierre Bourdieu, bem como a filosofia de valores desenvolvida por Carlos Valverde Mucientes. Pesquisar-se-á, por fim, o papel da literatura em diálogo com os temas apontados.

PALAVRAS-CHAVE: Escrita de si, Classe social, Trânsfuga, Pai.

\section{LE LANGAGE ENTRE DEUX MONDES DANS L'OEUVRE LA PLACE, DE ANNIE ERNAUX}

RÉSUMÉ : Cet article réfléchit sur les problèmes sociaux signalés dans l'ouvre La Place de l'écrivaine française Annie Ernaux, en mettant en relief l'éloignement entre l'auteur et son père, le personnage principal. L'analyse prendra en compte l'expression "transfuge de classe", créé par Pierre Bourdieu, ainsi que la philosophie des valeurs développée par Carlos Valverde Mucientes. Enfin, nous rechercherons le rôle de la littérature en dialogue avec les thèmes mentionnés.

\footnotetext{
${ }^{1}$ Mestranda do Programa de Pós-Graduação em Estudos da Literatura da Universidade Federal Fluminense (UFF). E-mail: vanfvjf@gmail.com
} 
MOTS-CLÉS : Écriture de soi, Classe Sociale, Transfuge, Père.

\section{INTRODUÇÃO}

Por volta dos anos 1960, em uma comuna da região da Normandia na França, um ex- operário que havia se tornado pequeno comerciante morreu em sua casa, onde também funcionava o seu café-restaurante. O homem tinha 67 anos e morava com a esposa, a qual explorava com ele aquele pequeno comércio. Sua única filha não morava mais na região, vivia com o marido e o filho em uma cidade turística dos Alpes, mas, naqueles últimos dias, estava a ajudar a mãe nos cuidados com o pai doente.

Em uma época em que os meios de comunicação não eram ainda muito acessíveis, a morte desse homem teria caído no esquecimento. Afinal, qual havia sido o seu "lugar" social? Camponês, ex-operário ou pequeno comerciante? Qual a importância de destacarmos sua existência? Em si, a morte desse homem só pôde vir à luz algum tempo depois por uma escritora de renome, professora universitária, enfim, por uma burguesa. $\mathrm{O}$ incômodo e o mal-estar em perceber-se em uma posição social não condizente com suas origens levaram a autora francesa Annie Ernaux a mergulhar na história do pai, na obra La place [O lugar] (1983), examinando a vida desse homem e deixando traços de uma reflexão sobre a própria existência, bem como uma profunda análise social.

Percebe-se, já no título do livro, uma polissemia, descoberta a cada passagem, ora indicando a posição social da figura paterna, ora da filha, outras vezes levantando reflexões sobre a condição da linguagem e da cultura enquanto instrumentos de poder. Mas, principalmente, a expressão identificadora da obra designa o lugar que aquele pai ocupava na vida da filha, ou seja, uma situação estabelecida por códigos sociais, nas palavras da autora "um afastamento de classe [...]. Como o amor separado" (ERNAUX, 1983, p. 17).

A escrita do real, percebida nas pistas autobiográficas e na biografia conhecida por meios externos ao livro, ao revelar-se também como uma escrita do social, atrelada a uma crítica ao período no qual se enquadra, aponta para um questionamento 
sobre o sentido da existência. Assim, ao mergulhar na vida e nas relações de um núcleo familiar, a narrativa acaba por retratar as mazelas provocadas pela classificação social, a qual não tem outro objetivo senão manter as relações de poder e o status quo, ao mesmo tempo em que estratifica a identidade do indivíduo.

Diante do diálogo entre a escrita de si e as questões sociais, nossa intenção é analisar o livro La Place, traçando um paralelo com o pensamento do sociólogo francês Pierre Bourdieu principalmente no que diz respeito ao conceito de "trânsfuga". O mal-estar sentido pela autora- narradora ao perceber-se como parte do universo burguês, ao mesmo tempo em que não se sente mais adequada no espaço físico e social no qual nascera e crescera, leva-nos também a investigar o papel da narrativa de Ernaux na representação dos anseios do sujeito moderno em sua relação com o capital, levando em consideração a perspectiva de Carlos Valverde Mucientes. Por fim, faremos uma reflexão sobre o papel da literatura no contexto apresentado.

\section{A crise de valores}

Annie Ernaux nasceu em 1940 em Lillebonne, comuna francesa na região da Normandia, em um contexto social modesto. A obra $O$ lugar inicia-se com o fato da aprovação da narradora nas provas para ingressar no cargo de professora titular em um liceu de Lyon e prossegue com as lembranças sobre a morte do pai. Em uma consulta biográfica, pode- se verificar a coincidência entre os fatos narrados e a vida da autora. Datas, locais, ocorrências revelam uma escrita referencial, ao mesmo tempo em que destaca questões sociais de uma época.

O pai da autora-narradora foi operário e, depois de muito esforço e economia, conseguiu abrir um pequeno comércio. Ela, por sua vez, tornou-se professora de Letras e escritora, fatos que a promoveram na hierarquia social e a distanciaram da vida junto à família. A nova profissão configurou sua entrada no mundo burguês, prosseguindo com uma mudança em suas relações com o próprio pai, as quais passaram a ser limitadas ao elementar, quase sem diálogos. O mal-estar causado por esse afastamento a levou a escrever sobre seu progenitor, em uma atitude de testemunha, de observadora, dando-lhe a palavra por meio de uma “escrita simples", sem poesia, alegria 
ou zombaria:

Desde há algum tempo sei que o romance é impossível. Para dar conta de uma vida dominada pela necessidade, não tenho o direito de tomar em primeiro lugar o partido da arte, nem procurar fazer qualquer coisa de "apaixonante" ou "comovente". Juntarei as palavras, os gestos, os gostos do meu pai, os factos marcantes da sua vida, todos os sinais de uma existência que também partilhei. (ERNAUX, 1983, p. 17)

Por meio de um registro fragmentado, como se flashes da memória fossem transportados para o papel, a autora-narradora conta, então, a evolução social de sua família, evocando a história de seus avós paternos, sob o ponto de vista de seu pai, voltando muitas vezes à própria infância, à adolescência ou à vida adulta. $\mathrm{O}$ avô havia trabalhado como carroceiro e o que a narradora ouvia sempre dizer era que ele não sabia ler nem escrever e se tornava violento quando via alguém da família lendo um livro ou um jornal.

A imagem do pai é construída, então, a partir do aspecto familiar, das dificuldades financeiras, do trabalho como camponês, do período de guerrilheiro, passando a operário, até chegar à condição de proprietário de um pequeno café-restaurante. Sempre preocupado com a linguagem e em disfarçar a própria condição social de origem:

Diante de pessoas que considerava importantes mostrava um embaraço tímido, nunca fazendo quaisquer perguntas. Em suma, comportando-se com inteligência. Esta consistia em perceber a nossa inferioridade e em recusá-la escondendo-a o melhor possível. (ERNAUX, 1983, p. 47)

Essa apreensão do pai ante situações sociais revela consequências de um sistema de valores estabelecido por meio de instrumentos simbólicos, os quais teriam o caráter ideológico de garantir a contínua superioridade da cultura dominante e manter 
o status quo. Sobre o assunto, o autor do livro Prelecciones de Metafísica Fundamental, Carlos Valverde Mucientes, ao analisar a filosofia dos valores, apontando perspectivas de diversos estudiosos acerca da relação entre bem e valor, recorda que um dos eventos mais prejudiciais para as pessoas de nossa época é o erro induzido pela sociedade burguesa capitalista de pensar o dinheiro como supremo valor. Assim:

Acertadamente Marx denunciou, já nos Manuscritos de 1844, que os homens da sociedade capitalista preferem "ter" do que "ser", e assim colocam sua essência fora de si mesmos, se alienam no dinheiro, nos bens de consumo, e não se preocupam em realizar sua essência enquanto pessoas, com toda a riqueza e beleza desta palavra. (MUCIENTES, 2009, p. 515, tradução nossa) ${ }^{2}$

A narrativa de Ernaux é fortemente marcada pelo desejo do pai de "parecer mais comerciante que operário", procurando "pôr-se no seu lugar" (ERNAUX, 1983, p. 34). Um personagem perseguido pelo medo de estar deslocado e pela obsessão sobre o que os outros pensariam dele e da família. Reflexos de um pensamento capitalista o qual, segundo Mucientes, "acostuma as pessoas a valorar tudo em dinheiro" (p. 515):

Ninguém em Y..., nas classes médias, comerciantes do centro, empregados de escritório, queria ter o ar de 'chegado do campo'. Parecer camponês significa que não se é evoluído, sempre em atraso relativamente à moda, na linguagem, no vestuário, no andar. (ERNAUX, 1983, p. 55)

Em suas preleções de metafísica, Mucientes aborda conceitos relacionados ao Ser, afirmando, após contrastar opiniões emitidas por outros autores ao longo da história, que todo ente tem em si mesmo um valor, pois o Ser é intrinsecamente único,

2 “Acertadamente denunció Marx, ya en los Manuscritos de 1844, que los hombres de la sociedad capitalista prefieren el "tener" que el "ser", y así ponen su esencia fuera de sí, si alienan en el dinero, en los bienes de consumo, y no se reocupan de realizar su esencia de personas con toda la riqueza y la belleza de esta palabra (MUCIENTES, 2009, p. 515)." 
verdadeiro e bom. Mucientes também aponta como uma das tarefas mais nobres do ser humano o ato de descobrir, criar e transmitir verdadeiros valores, sendo, em contrapartida, um dos delitos mais graves, a difusão de antivalores, ou a negação de valores verdadeiros. A pessoa humana é, então, o único ser no mundo capaz de descobrir valores, entendê-los enquanto tais, e optar refletidamente entre os diversos valores existentes.

Nesse ponto, a concepção defendida por Carlos Valverde Mucientes é bem representada na obra de Annie Ernaux, pois a narrativa aborda os valores atribuídos pelo personagem-pai a questões econômicas, à educação, à cultura, à família e à sociedade. Ao passar boa parte da vida submetido às leis do mercado, esse homem supervaloriza bens materiais e relações pautadas no retorno financeiro, ao mesmo tempo que demonstra uma enorme preocupação com o verniz social e, consequentemente, investe nos estudos da filha como forma de assegurar-lhe uma colocação social. Essa atitude aponta para uma crise de valores vivenciada pela sociedade moderna, na qual o capital intervém até mesmo nos laços parentais, podendo comprometer a afetividade nas relações. Nas palavras de Mucientes:

\begin{abstract}
A dolorosa tragédia das civilizações europeias do século XX foi ter convertido a pessoa em "algo", em coisa, em peça de uma máquina anônima para a guerra [...]. Foram as ditaduras políticas e seguem sendo as ditaduras do economicismo capitalista. A prevalência e a sobrevalorização do abstrato, do impessoal - o partido, a raça, a sociedade sem classes, o produto, o benefício econômico - acaba por adiar e destruir a pessoa. (MUCIENTES, 2009, p. 1104, tradução nossa) ${ }^{3}$
\end{abstract}

\footnotetext{
3 "La dolorosa tragedia de las civilizaciones europeas del siglo XX fue haber convertido a la persona en "algo", en cosa, en pieza de una máquina anónima para la guerra, en número sin rostro en un campo de concentración, en ciego esclavo del partido, en animal-máquina que produce y consume, en el hombre unidimensional y amorfo que ya denunció Herbert Marcuse. Fueron las dictaduras políticas y siguen siendo las dictaduras del economicismo capitalista. La prevalencia y la sobrevaloración de lo abstracto, de lo impersonal - el partido, la raza, la sociedad sin clases, el producto, el beneficio económico - acaba por posponer y aun destruir a la persona. (MUCIENTES, 2009, p. 1104)"
} 
O mal-estar provocado por essa inversão de valores é pontuado por Ernaux na abertura da obra, quando a narradora rememora o dia em que foi aprovada nas provas para ingressar no cargo de professora titular em um liceu de Lyon. Naquela ocasião, ela escolheu como texto de base de sua prova-aula a obra Pai Goriot, cuja trama é centrada em um homem explorado e abandonado por suas duas filhas, após ter dedicado sua vida a elas. Percebe-se já nesse evento uma necessidade da filha em pensar sua relação com o pai e o afastamento ocorrido desde sua adolescência entre os dois.

\section{O sentido da existência}

A importância dada à existência em si mesma, sem influência de um Deus ou de qualquer ideologia parece ser um objetivo perseguido pela escrita de Annie Ernaux. Embora não seja uma busca explicitamente declarada, nota-se a procura da narradorapersonagem por extrair de cada reminiscência elementos os quais possam trazê-la algum sentido sobre a própria existência. A narrativa mostra com detalhes os dias que seguiram à morte do personagem-pai, desde o cheiro de "mofo adocicado" seguido do odor "terrível de flores esquecidas num jarro de água estagnada", até os pratos servidos aos visitantes no velório. Os detalhes de sua casa, onde ocorreu o luto, são descritos com precisão, a ponto de transportar o leitor para dentro da memória da autora e a interpelar junto a ela qual seria o real significado de sua - nossa - existência.

De certo, o enterro daquele homem não ocorrera logo após o funeral do corpo, mas muitos anos antes na vida da narradora-personagem, quando esta era ainda adolescente e começara a frequentar o universo burguês por meio de suas amizades na escola. O luto revivido pela literatura parece ter sido, na verdade, um retorno à vida, como uma escrita da existência, capaz de reatar os laços rompidos por distanciamento de classes. $\mathrm{O}$ texto literário assinala, então, uma ânsia pelo retorno à afetividade. $\mathrm{O}$ mal-estar da burguesa é transportado para uma escrita de si, na qual o "eu" parece ser indagado por meio de um olhar analítico da vida do outro.

Ainda que pese a responsabilidade pela própria existência e a culpa por ter se 
distanciado do pai, a autora-narradora-personagem Annie Ernaux manifesta sua escolha de escrever um livro de memórias, criando uma imagem de si e de seu progenitor, em uma dimensão que ultrapassa o individual. Sendo a escrita o seu modo de resgatar o passado e denunciar aspectos da sociedade de classe, Ernaux tenta reunir pensamentos, falas e ações em um processo de construção da própria essência, sem se apegar a princípios absolutos. Ao cumprir o ofício propulsor de seu status na hierarquia social, a então escritora parece tentar representar um sentimento não vivido, ou talvez um afeto atravessado por fatores que não dependiam de sua escolha.

\section{A essência construída no entre-lugar}

Além de apresentar registros da afetividade familiar e de denunciar as disparidades sociais de duas classes, Ernaux também se justifica quanto ao uso da linguagem, ao mesmo tempo em que questiona o julgamento linguístico encontrado dentro do contexto literário. A autora-narradora evoca Proust ao abordar a vergonha do pai quanto ao dialeto normando falado pelos avós, e critica a atitude desse renomado autor em registrar com "arrebatamento" os arcaísmos pronunciados no francês popular por sua criada, sendo que o comportamento não seria o mesmo se tais "incorreções" fossem ditas pela mãe. Ernaux desaprova, com isso, a escolha da tradição literária pela língua francesa nacional escolar e pelo destaque dado à cultura letrada.

A escrita fragmentada adotada na narrativa ernausiana demonstra ainda uma forma de apreensão da vida, colocando em questão a estrutura linear do romance tradicional, bem como aponta para a não linearidade do sujeito moderno. Ao longo da obra, a autora-narradora deixa pistas de uma ânsia por tentar encontrar o sentido da vida, eliminando, a cada trecho, as barreiras que pudessem impedi-la de fazer emergir do mergulho no passado, o humano do ser. Os fragmentos da memória se juntam conforme peças de um quebra-cabeça, para tentar dar vida a duas existências as quais pareciam até então esvaziadas pelas determinações da cultura dominante, fosse por imposição de uma língua padrão, de um status social, ou de um valor econômico.

Dessa forma, a obra não se restringe à escrita de si, ela aponta questões rela- 
cionadas ao meio relativo a cada um dos dois mundos da autora-narradora. Em algumas passagens, a narradora revela a preocupação de seus pais em proporcionar uma boa educação para ela. E é justamente por meio da persistência nos estudos que Ernaux muda de posição social, ingressando em uma classe diplomada:

Ele levava-me de casa à escola em cima da bicicleta. Barqueiro de duas margens, sob a chuva e o sol. Talvez o seu maior orgulho, ou mesmo a justificação da sua existência: que eu pertencesse ao mundo que o tinha desprezado. Ele cantava: É o remador que nos leva à roda. (ERNAUX, 1983, p. 89)

Ao longo da obra, percebe-se a necessidade da autora em demonstrar sua sensação de alienação ao se ver diante dos dois mundos em que sua vida se dividira. Analisando sob o ponto de vista teórico, essa separação entre classe operária e classe burguesa faz referência ao que o sociólogo francês Pierre Bourdieu aponta como ambivalência, ao abordar a situação de pais originários de meios desfavorecidos e o sucesso escolar dos filhos, os quais cumprem o destino de "trânsfugas", ou seja, vivenciam a contradição de terem o sucesso associado a uma espécie de traição das próprias origens (BOURDIEU, 1998, p. 14).

A epígrafe de $O$ lugar já anuncia a necessidade de se escrever sobre essa quebra de fidelidade, com a citação de Jean Genet: “Arrisco uma explicação: escrever é o último recurso quando se traiu". No meio da narrativa, em um dos fragmentos, a narradora faz alusão a uma busca de pertencimento, a um desejo de reunir palavras, fatos importantes, por meio de uma escrita simples, na qual o "eu" narrativo tenta preencher lacunas identitárias no nível da língua. A trajetória social da narradora trânsfuga é permeada pelo investimento na escolaridade por parte do pai, sendo elementos essenciais para a reflexão de um projeto existencial pautado no distanciamento. Em certo ponto do texto, em uma frase "solta", a narradora confessa estar escrevendo porque já não tinham mais nada para dizer um ao outro:

Eu pensava que ele não podia fazer mais nada por mim. As suas palavras e as suas ideias não podiam ser usadas nas aulas de Francês ou de Filosofia, nas residências com sofás de veludo vermelho 
das amigas da escola. No Verão, através da janela aberta do meu quarto, ouvia o barulho da sua enxada alisando regularmente a terra revolvida. (ERNAUX, 1983, p. 66)

Annie Ernaux traz à luz a importância do fluxo entre duas culturas, relatando os momentos de profundo incômodo ao ver-se dentro algum enquadramento social considerado burguês. A cultura acumulada por ela por meio dos estudos e da nova profissão era algo que não causava o menor interesse no progenitor. A narradora destaca esse desinteresse ao contar a trajetória do pai quando este era soldado e regressou de Paris não querendo voltar à "cultura", considerada por ele apenas como o "trabalho da terra", sendo que o sentido espiritual da palavra era considerado inútil para ele.

Esse fluxo, tanto no âmbito cultural quanto no social, é apresentado pela autora- narradora ao mencionar momentos de sua vida no campo, junto à família, e, outras vezes, ao destacar a vida na metrópole, partilhada com o filho e o marido, o qual, nascido e criado no universo burguês, não demonstrava qualquer interesse pelos parentes da esposa. Além disso, várias passagens rememoradas ocorrem dentro de meios de transporte, o que também simboliza a crise de identidade vivida pela narradora, e o incômodo de estar no "meio" de dois mundos. Ao mesmo tempo, esses espaços são carregados de reflexão sobre as diferenças entre as classes, os costumes e as culturas, apontando para a possibilidade de entre-lugar:

No comboio de regresso, no domingo, procurei distrair meu filho para que se mantivesse tranquilo, os passageiros de primeira não gostam de barulho e de crianças traquinas. De repente, uma estupefação, 'agora, sou realmente uma burguesa' e 'é demasiado tarde'. (ERNAUX, 1983, p. 17)

No entanto, mais do que mostrar a multiplicidade de identidades do sujeito e dos fatores envolvidos na tecedura da vivência da personagem-narradora com o pai, Ernaux deslinda com minúcia o processo de transição entre todos os "lugares" envolvidos na trama. No início do texto, a narradora relata ter sentido cólera e uma espécie de vergonha pela aprovação na prova para ser contratada como professora titular. Logo depois, ainda na adolescência, vem a consciência de que o pai não a percebe da 
mesma forma que ela se vê e que os dois têm concepções de mundo muito diferentes. É na fase adulta que o choque da autopercepção enquanto burguesa a leva à necessidade de escrever sobre o passado, a buscar uma essência no entre-lugar, a pensar em uma possibilidade de identidade construída no entrelaçamento de duas culturas, de duas vidas, sem que uma tivesse que excluir ou rejeitar a outra, conforme ocorre com a padronização de identidades imposta pela sociedade.

A última passagem do livro comprova que a personagem-narradora transpôs as fronteiras entre as duas classes. Na cena rememorada, ela está em um supermercado e encontra uma ex-aluna a qual estava então trabalhando no caixa. As duas conversam rapidamente, a professora pergunta se ela está gostando do emprego e a menina responde que não conseguiu fazer o curso técnico, as duas despedem-se e a antiga aluna continua a passar as mercadorias no caixa em um movimento automático.

\section{Considerações finais}

Em 1979, Didier Eribon, ao entrevistar Pierre Bourdieu, fez-lhe uma pergunta que vem ao encontro de nossas reflexões ao longo deste artigo: "Como se poderá constituir uma oposição à imposição dos valores dominantes?”. A resposta, segundo o sociólogo, estaria na arte de resistir às palavras, em dizer apenas o que se quer dizer, ou seja, de se livrar de discursos carregados de sentido social, de palavras emprestadas, censuradas interna e externamente, ou faladas por "porta-vozes que são eles próprios falados" (BOURDIEU, 2003, p. 20). Nesse sentido, a escrita de Annie Ernaux analisada neste artigo mostra-se como uma forma de engajamento na luta pela desarticulação das estruturas de dominação.

Considerando que a linguagem e a cultura são instrumentos simbólicos significativos na manutenção das hierarquias, a literatura ernausiana cumpre o seu papel na resistência, a partir da denúncia das disparidades sociais e suas influências nos laços afetivos. $\mathrm{O}$ ato de fragmentação do texto, não propondo um começo ou um fim, aponta um desejo de encontrar algum conforto por meio da escrita, da expressão das memórias. Ao mesmo tempo, ao deixar pistas dos estragos causados pela estratificação social, bem como pela supervalorização do capital, O lugar nos deixa também um 
questionamento sobre o sentido da existência e o lugar do sujeito na sociedade. Nas páginas precedentes, tentamos explorar esses temas a partir de uma escrita do luto, na qual a autora-narradora sente-se no dever de escrever sobre a história do pai e também a própria, fazendo emergir lembranças, para então tentar construir um projeto existencial.

É certo que em algum momento da vida seremos confrontados com a experiência da morte de um parente ou de alguém muito próximo de nós, por quem certamente temos grande afeto. No entanto, não esperamos que isso nos aconteça realmente. Somente quando a perda ocorre de fato, é possível tomar consciência e refletir sobre a ausência. Nesse sentido, a escrita do real proposta por Ernaux, ainda que tenha sido preenchida em alguns pontos pelo imaginário criativo, permite-nos um questionamento sobre a nossa própria existência, retomando o passado e refletindo sobre o presente, sem direcionarmos o foco ao futuro, conforme propõe a sociedade do consumo. Ao restabelecer os elos afetivos por meio da dedicação da escrita ao pai e ao apresentar a possibilidade de um intercâmbio entre duas culturas, em uma existência construída no entre-dois, Ernaux tira a cultura hegemônica da zona de conforto, mostrando que há uma possibilidade de buscarmos a Humanidade do Ser e que isso depende do engajamento de todos e de cada um.

\section{REFERÊNCIAS BIBLIOGRÁFICAS}

BOURDIEU, Pierre. A Escola conservadora: as desigualdades frente à escola e à cultura. In: NOGUEIRA, M. A \& CATANI, A (orgs.). Escritos de educação. Tradução de Aparecida Joly Gouveia. Rio de Janeiro: Vozes, 1998.

O poder simbólico. Tradução Fernando Tomaz. Rio de Janeiro: Bertrand Brasil, 1989. Coleção memória e sociedade. 
Questões de Sociologia. Tradução de Miguel Serras Pereira. Fim de século- Edições, Sociedade Unipessoal, LDA., Lisboa, 2003.

BOURDIEU, P. ; PASSERON, C. Les héritiers: les étudiants et la culture. Paris: Éditions de Minuit, 1964.

ERNAUX, Annie. O Lugar. Tradução de António Moreira e Joel Goes. Lisboa: Fragmentos, 1983.

. Écrire la vie. Paris: Gallimard, 2011.

La place. Paris: Gallimard, 1983.

Le vrai lieu. Paris: Gallimard, 2014.

MUCIENTES, Carlos Valverde. Prelecciones de Metafísica Fundamental. Madrid:

Biblioteca de Autores Cristianos, 2009. 